\title{
A study on change of fatty acids profile in ghee adulterated with palm oil
}

\author{
Tanmay Hazra, CVK Sudheendra, Kunal Kumar Ahuja, Rohit GSindhav and Vimal M Ramani
}

Received: 04 January 2020 / Accepted: 21 January 2020 / Published online: 18 May 2020

(C) Indian Dairy Association (India) 2020

\begin{abstract}
Ghee, is clarified butter or anhydrous milk fat, has an integral relation with Indian culinary culture. Due to the importance and seasonal decline in the production; unscrupulous traders tend to add cheap vegetable oils like palm oil in ghee. The composition of milk fat and oil vary in terms of fatty acids. Milk contains mainly short and medium chain fatty acids whereas vegetable oil contains long chain fatty acids. Due to different fatty acids composition between milk fat and palm oil, we tried to exploit this fatty acids difference to identify the adulteration of palm oil in ghee, using Gas chromatography. Study suggested that due to palm oil adulteration in ghee, the concentration of short chain fatty acids get decreased and long chain saturated and unsaturated fatty acids showed an increase. In addition to the above, change was also observed in the ratio of the total of saturated fatty acids to unsaturated fatty acids. Fatty acids analysis could be very effective for the detection of palm oil adulteration in ghee to the tune of $5 \%$. Our current study suggested that fatty acids study was able to detect foreign fat like palm oil in milk fat but this study is not suitable to confirm the type of foreign fat in milk fat or ghee.
\end{abstract}

Keywords: Adulteration, Butyric acid, Ghee, Gas liquid Chromatography, Linoleic acid, Palm oil

Tanmay Hazra $(\bowtie)$, CVK Sudheendra, Kunal Kumar Ahuja, Rohit G Sindhav and Vimal M Ramani

College of Dairy Science, Kamdhenu University, Amreli, Gujarat, 365 601 India

Email: tanmayhazra08@gmail.com
India is the highest milk producing country in the world. In India after liquid milk $(\sim 46 \%)$, ghee $(\sim 28 \%)$ is the second largest dairy product that is consumed throughout the country (GAIN, 2014). A very complex situation arises during the lean season of the year i.e., in the summer months (May to August) when the supply of milk and ghee drastically reduces. In this situation, unscrupulous traders use to add cheaper fats such as vegetable oils (palm oil, cottonseed oil etc.) in ghee, for gaining more money. Traditionally such type of adulteration is checked by analysing different fat constants of milk fat like- Reichert-Meissl value (RM value), Polenske value and Butyro Refractometer (BR) reading. Recently, dry fractionation technique coupled with fat constants analysis, was proved more suitable than simple fat constants analysis, to detect adulteration in ghee (Kumar et al. 2017); however, these technique are time consuming.

Recent trend being followed by the unscrupulous traders adulterate ghee in such a way that cannot be detected by simple fat constant analysis based approaches. Very recently, Pathania et al. (2020) applied a new approach of zooming in and superimposing of selected peaks in the chromatograms of triglycerides (using Gas chromatography), to detect refined palm oil along with other manipulated fats. Detection of palm oil adulteration in ghee is always a challenge for the scientific community; as there are very few studies available for the detection of oil in ghee (Ramani et al. 2019). Bector and Sharma (2002) were able to detect palm oil adulteration in ghee using a colorimetric test; however these test was unable to detect BHA added ghee and ghee adulterated with palm oil. Researchers developed methods using fourier transform - near infrared (FTNIR) and fourier transform - middle infrared (FT-MIR) spectroscopy to identify palm oil adulteration in ghee (Mehta et al. 2018; Aparnathi et al. 2019). However, FT-IR based analytical approaches were not suitable to detect palm oil in ghee lower than 10\% level.(Aparnathi et al. 2019)

Fatty acid composition of milk fat is greatly affected by season, breed, species, parity, stage of lactation etc. (Kumar et al. 2015). Bharwade et al. (2017) reported that short and medium chain fatty acids were predominated in ghee. Butyric acid is a unique fatty acid in milk fat; however, change in butyric acid indicated the presence of adulteration in ghee (Mehta, 2013). Upadhyay et 
al. (2018) reported that for both pure cow and pure buffalo ghee, the major fatty acids were myristic acid $\left(\mathrm{C}_{14: 0}\right)$, palmitic acid $\left(\mathrm{C}_{16: 0}\right)$, stearic acid $\left(\mathrm{C}_{18: 0}\right)$ and oleic acid $\left(\mathrm{C}_{18: 1}\right)$. Orsavova et al. (2015) reported that major fatty acids in palm oil were palmitic acid, oleic acid, linoleic acid and stearic acid; however, those researchers reported the absence of short chain fatty acids. Rebechi et al. (2015) reported that fatty acids ratio $(\mathrm{C} 10: 0 / \mathrm{C} 8: 0, \mathrm{C} 12: 0 / \mathrm{C} 10: 0$, C14:0/C12:0 and C14:0/C18:) could not able to detect body fat adulteration in milk fat. In a different study Kumar et al. (2015) successfully used selected fatty acid ratios (C14:0/C18:1 and C14:0/ $\mathrm{C} 18: 2)$ as a marker for the detection of soybean oil adulteration in ghee.

Milk fat is unique and distinct from other fats. It is the only fat that contains short chain fatty acids, while vegetable oils are rich in linoleic acid (Kumar et al. 2015). Therefore, by keeping all these aspects of the fatty acid composition of different oils/fats, an attempt was made to detect adulteration in ghee with palm oil by fatty acid analysis using Gas chromatography technique.

Mix milk were collected from a local dairy farmers ofAmreli district, Gujarat. The ghee was prepared by creamery butter method (De, 2011). The final temperature of clarification was $110^{\circ} \mathrm{C}$. The clarified fat was filtered using coarse filter paper to obtain ghee and stored in airtight glass bottles at room temperature.

Palm oil was procured from a local market of Amreli city. For the preparation of adulterated ghee samples, pure ghee samples were heated to $60-70^{\circ} \mathrm{C}$ for $10 \mathrm{~min}$ before adding and mixing of palm oil. The adulterated ghee samples were prepared by the addition of palm oil in four different proportions $(5,10,15$ and $20 \% \mathrm{w} / \mathrm{w})$ into pure ghee.

Methylation of the above samples for making esters was done by the sealed tube method of DeMan (1964) as modified by Luddy et al. (1968). An incubation temperature of $75^{\circ} \mathrm{C}$ was used instead of $60^{\circ} \mathrm{C}$.

Ester tubes were broken at the time of analysis and the sample was injected into the Gas chromatography column without any further treatment. Fatty acid profile of the above said samples in methylated form were analyzed in the capillary column (length 30 $\mathrm{m}$, internal diameter $0.25 \mathrm{~mm}$ ) using Gas Chromatography (Thermo Fisher Scientific - Trace 1110) equipped with a flame ionization detector $\left(240^{\circ} \mathrm{C}\right)$. The other conditions like Total Flow: $79 \mathrm{ml} / \mathrm{min}$ $\left(\mathrm{N}_{2}\right)$, Column Flow: $1.49 \mathrm{ml} / \mathrm{min}$, Pressure: $13.4 \mathrm{Kpa}$ and Purge flow: $3 \mathrm{ml} / \mathrm{min}$ were set for further analysis.

The reference standards (Loba Chemical) of different fatty acids methyl esters were used to standadize a 37 minutes Gas chromatography programme. The sample was injected at an initial temperature of $70^{\circ} \mathrm{C}$ maintained for 3 min and then raised after the emergence of butyric acid peak to $150^{\circ} \mathrm{C}$ by holding for $3 \mathrm{~min}$ till the emergence of myristic acid $\left(\mathrm{C}_{14: 0}\right)$ peak with a ramp rate of $5^{\circ} \mathrm{C} / \mathrm{min}$, then again raised up to $200^{\circ} \mathrm{C}$ with same ramp rate till the emergence of oleic acid $\left(\mathrm{C}_{18: 1}\right)$ and then maintained at $200^{\circ} \mathrm{C}$ for 5 min until emergence of the peak of linolenic acid on chromatograph. By using the above specifications, chromatographs of different fatty acids profile were obtained and the percentage of each fatty acid was calculated and

Table 1 Fatty acid profile (percentage of weight) of pure ghee and palm oil and adulterated ghee

\begin{tabular}{|c|c|c|c|c|c|c|}
\hline \multirow[t]{2}{*}{$\overline{\text { Fatty acids }}$} & \multirow{2}{*}{$\frac{\text { Type of }}{\text { Pure ghee }}$} & \multicolumn{2}{|l|}{ fat/oil** } & \multirow{2}{*}{$\begin{array}{l}\text { Level of } \\
10 \% \text { PO }\end{array}$} & \multicolumn{2}{|c|}{ Adulteration $* *$} \\
\hline & & Palmoil & $5 \% \mathrm{PO}$ & & $15 \% \mathrm{PO}$ & $20 \% \mathrm{PO}$ \\
\hline$\overline{\mathrm{C}_{4 \cdot 0}}$ & $2.43 \pm 0.22$ & 0.00 & $1.52 \pm 0.008$ & $1.28 \pm 0.002$ & $1.03 \pm 0.01$ & $1.01 \pm 0.006$ \\
\hline $\mathrm{C}_{8: 0}^{0.0}$ & $0.62 \pm 0.007$ & 0.00 & $0.61 \pm 0.003$ & $0.45 \pm 0.0006$ & $0.43 \pm 0.003$ & $0.39 \pm 0.01$ \\
\hline $\mathrm{C}_{10.0}^{8.0}$ & $1.59 \pm 0.05$ & 0.00 & $1.39 \pm 0.001$ & $1.29 \pm 0.001$ & $1.16 \pm 0.001$ & $1.01 \pm 0.004$ \\
\hline $\mathrm{C}_{12: 0}^{10.0}$ & $1.95 \pm 0.01$ & 0.00 & $1.37 \pm 0.014$ & $1.12 \pm 0.0007$ & $1.10 \pm 0.005$ & $1.08 \pm 0.01$ \\
\hline $\mathrm{C}_{16: 0}^{14.0}$ & $29.9 \pm 1.64$ & $39.68 \pm 0.015$ & $30.42 \pm 0.044$ & $31.36 \pm 0.02$ & $32.04 \pm 0.21$ & $32.12 \pm 0.81$ \\
\hline $\mathrm{C}_{18.0}^{10.0}$ & $18.24 \pm 0.31$ & $4.01 \pm 0.017$ & $17.14 \pm 0.78$ & $14.43 \pm 0.19$ & $12.34 \pm 2.25$ & $11.89 \pm 7.76$ \\
\hline $\mathrm{C}_{18: 1}^{18.0}$ & $30.94 \pm 0.53$ & $43.55 \pm 0.04$ & $34.17 \pm 0.84$ & $35.39 \pm 0.02$ & $36.29 \pm 0.27$ & $36.51 \pm 1.13$ \\
\hline $\mathrm{C}_{18.2}^{10.1}$ & $1.91 \pm 0.037$ & $11.18 \pm 0.007$ & $2.22 \pm 0.027$ & $4.18 \pm 0.16$ & $5.68 \pm 1.59$ & $6.02 \pm 6.01$ \\
\hline $\mathrm{C}_{18.3}^{18: 2}$ & $1.57 \pm 0.019$ & $0.246 \pm 0.001$ & $1.36 \pm 0.011$ & $1.22 \pm 0.003$ & $1.15 \pm 0.02$ & $1.12 \pm 0.06$ \\
\hline \multicolumn{7}{|l|}{ Total unsaturated fatty acids } \\
\hline Sum of $\mathrm{C}_{4: 0}$ to $\mathrm{C}_{16: 0}$ fatty acids & $16.99 \pm 0.05$ & $0.96 \pm 0.005$ & $14.30 \pm 0.01$ & $12.92 \pm 0.001$ & $12.09 \pm 0.005$ & $11.32 \pm 0.03$ \\
\hline Sum of $\mathrm{C}_{18: 0}^{4: 0}$ to $\mathrm{C}_{20: 0}^{16: 0}$ fatty acids & $83.02 \pm 0.42$ & $99.03 \pm 0.01$ & $85.74 \pm 0.28$ & $86.99 \pm 0.06$ & $87.90 \pm 0.73$ & $88.09 \pm 2.64$ \\
\hline
\end{tabular}

** Data represent the mean $\pm \mathrm{SE}$ of six determinations 
compared. The identical conditions as mentioned above and the retention time of these fatty acids were used to identify the fatty acids in the ghee (pure and adulterated) samples.

Pure ghee and palm oil revealed a wide difference in their fatty acid composition. Fatty acids composition of both palm oil and pure ghee is given in table 1 . There were wide differences between the fatty acids composition of milk fat (ghee) and palm oil. It was observed from table 1 that in pure ghee short chain fatty acids like $\mathrm{C}_{4: 0}, \mathrm{C}_{6: 0}, \mathrm{C}_{8: 0}, \mathrm{C}_{10: 0}$ and $\mathrm{C}_{12: 0} ; 2.43,0.73,0.62,1.59$ and $1.95 \%$, respectively; however, in case of palm oil no short chain fatty acids were determined. However, even myristic acid $\left(\mathrm{C}_{14: 0}\right)$ was also found to be very nominal in the palm oil $(0.96 \%)$ as compared to pure ghee $(9.69 \%)$. The four main fatty acids in palm oil were identified as palmitic $\left(\mathrm{C}_{16: 0}\right)$, stearic $\left(\mathrm{C}_{18: 0}\right)$, oleic $\left(\mathrm{C}_{18: 1}\right)$ and linoleic $\left(\mathrm{C}_{18: 2}\right)$ acids at $39.68,4.01,43.55$ and $11.18 \%$, respectively. Earlier Rebechi et al. (2015) reported that every oil or fat has different unique signature fatty acids make up; hence, ghee or pure milk fat content mostly short or medium chain fatty acids. However, among unsaturated fatty acids oleic acids were predominated in pure milk fat or ghee.

Comparing the palm oil to ghee, it was observed in table 1 that $\mathrm{C}_{16: 0}, \mathrm{C}_{18: 1}$ and $\mathrm{C}_{18: 2}$ were higher in case of palm oil than ghee. Though the $\mathrm{C}_{18: 3}$ and $\mathrm{C}_{20: 0}$ were $1.57 \%$ and $0.46 \%$, those were higher in ghee as compared to palm oil. It was also observed in table 1 that mono-unsaturated fatty acids (oleic) in palm oil were higher as compare to ghee. However, total saturated fatty acids were higher in ghee as compared to palm oil. Our results were in line with the earlier observation of Kumar et al. (2015) who reported that short chain fatty acids were predominated in ghee, however, there were no short chain fatty acids identified in vegetable oil. Mehta (2013) analyzed different market samples of ghee and concluded that saturated fatty acids were predominated than unsaturated fatty acids in ghee. Same type of observation was earlier recorded by Upadhyay et al. (2018).

Earlier workers also suggested that unsaturated fatty acids were predominated in vegetable oil (Kumar et al. 2015; Upadhyay et al. 2018). Both ghee and vegetable oil contained very high amount of oleic acid; although the concentration of oleic acid was higher in the case of palm oil as compared to pure ghee. In a different study Upadhyay et al. (2018) reported that total unsaturated fatty acids were higher both in depot fat and vegetable oil.

The effect of palm oil adulteration was also significant on some selected fatty acids like butyric acid $\left(\mathrm{C}_{4: 0}\right)$ that was found to be decreased when adulterated with palm oil (Table 1). However, oleic and linoleic acids were increased during adulteration of palm oil and this significance difference even visible after $5 \%$ level of palm oil adulteration in pure ghee (Table 1).

From table 1, it was also revealed that during palm oil adulteration in ghee; the sum of saturated fatty acids decreased; however, sum of un-saturated fatty acids increased quantitatively. It was also observed that change of the fatty acids in ghee depends on the percentage of added palm oil in ghee. It was recorded from table 1 that total saturated fatty acid in pure ghee, pure ghee +5 $\%$ palm oil, pure ghee $+10 \%$ palm oil, pure ghee $+15 \%$ palm oil and pure ghee $+20 \%$ palm oil were $62.29,59.12,56.87$ and 55.76 $\%$, respectively; however, the total un-saturated fatty acids were $34.42,37.75,40.79,43.12$ and 43.65 , respectively. This effect was clearly identified even in $5 \%$ level of palm oil adulteration in ghee. Recently, FSSAI has implemented to detect vegetable oil adulteration in ghee using HPLC based method but that said method unable to detect palm oil in ghee (Ramani et al. 2019). However, our study suggested that palm oil could be efficiently detected by fatty acid analysis; especially the ratio of the sum of saturated fatty acids to sum of unsaturated fatty acids could be effectively use as a potent markers to detect palm oil as an adulterant in ghee. Rebechi et al. (2015) and Kumar et al. (2015) reported that during adulteration of both vegetable oil and depot fat in milk fat or ghee; fatty acids used to be changed and this change of fatty acid even visible very low level of foreign fat adulteration. So, from the current study it could be concluded that fatty acids study able to detect foreign fat in milk fat but this study is not fruitful to confirm type of foreign fat in milk fat.

\section{Conclusions}

The present study revealed that the palm oil could be easily detected at $5 \%$ level in ghee/milk fat when butyric, oleic and linoleic acids were used as a marker. On the other side, ratio of sum of the total of saturated to unsaturated were found useful marker for detecting the different levels of adulteration in ghee. It can be concluded that fatty acids analysis could be very effective for the detection of palm oil adulteration in ghee to the tune of 5 $\%$; but change of fatty acid could even observed during other types of foreign fat adulteration in milk fat or ghee.

\section{Acknowledgments}

All authors are thankful to Vice-Chancellor and Director of Research, Kamdhenu University Gujarat for providing all facilities to carry out this research project. This research did not receive any specific grant from funding agencies in the public, commercial or not-for-profit sectors.

\section{References}

Aparnathi KD, Sharma S, Antony B, Mehta BM (2019) Development of method for detection and quantification of foreign oils and fats in ghee (heat clarified milk fat) using FT NIR spectroscopy coupled with chemometric. Indian J Dairy Sci 72: 12-22

Bector BS, Sharma V (2002) Physico-chemical characteristics of ghee adulterated with palm oil and its detection. NDRI Annual report, pp. 44-45.

Bharwade M, Balakrishnan S, Chaudhary N, Jain AK (2017) Fatty acid profile and physico-chemical characteristics of milk lipids of Kankrej cow. Inter J Curr Microbiol Appl Sci 6: 3035-3047 
De S (2011) Outlines of Dairy Technology. Oxford University Press, New Delhi

DeMan JM (1964) Determination of the fatty acid composition of milk fat by dual colomn temperature programmed GLC. J Dairy Sci 47: 546-547

GAIN (2014) India Dairy and Products annual. Gain Report No: IN 4089, Recent GAIN Publications. https://gain.fas.usda.gov Accessed 23 August 2019

Kumar A, Upadhyay N, Gandhi K, Naik SN, Sharma V (2017) Detection of adulteration in anhydrous milk fat (ghee) using season variation in Butyro-refractometer reading studied by employing dry fractionation technique. Indian J Dairy Sci 70: 563-570

Kumar A, Upadhyay N, Padghan P, Gandhi K, Sharma V (2015) Detection of vegetable oil and animal depot fat adulteration in anhydrous milk fat (ghee) using fatty acid composition. MOJ Food Process Technol 1: $13-19$

Luddy RE, Herb SF, Magidman P (1968) A rapid method and quantitative procedure for the preparation of methyl esters of butter oil and other fats. J Am Oil Chem Soc 45: 549-552

Mehta BM, Antony B, Sharma S, Ratnam K, Aparnathi KD (2018) Comparative appraisal of FT MIR spectra of ghee (heat clarified milk fat) with that of the mutton tallow and vegetable fat. Indian J Dairy Sci 71: 240-245
Mehta M (2013) Consumption pattern and fatty acid composition of ghee. Food Sci Research J 4: 116-120

Orsavova J , Misurcova L, Ambrozova VJ, Vicha R, Mlcek J (2015) Fatty Acids Composition of Vegetable Oils and Its Contribution to Dietary Energy Intake and Dependence of Cardiovascular Mortality on Dietary Intake of Fatty Acids. Int J Mol Sci 16: 12871-12890

Pathania P, Sharma V, Arora S, Rao PS (2020) A novel approach to detect highly manipulated fat adulterant as Reichert-Meissl value-adjuster in ghee (clarified butter) through signature peaks by gas chromatography of triglycerides. J Food Sci Technol 57: 1-9

Ramani A, Hazra T, Parmar MP, Sindhav RG, Ramani VM (2019) Simple rapid technique for detection of palm oil in ghee. Indian J Dairy Sci 72: 441-444

Rebechi SR, VElez MA, Vaira S, Perotti MC (2015) Adulteration of Argentinean milk fats with animal fats: detection by fatty acids analysis and multivariate regression techniques. Food Chemistry. doi.org/10.1016/j.foodchem.2015.07.107

Upadhyay N, Kumar A, Lal D, Kant R, Goyal A (2018) Detection of groundnut oil and goat body fat adulteration in ghee using principal component analysis on fatty acid profile. Indian J Dairy Sci 71 : $464-472$ 